\title{
A cultural change to enable improved decision-making in forensic science: a six phased approach
}

\author{
Earwaker, H., Nakhaeizadeh, S., Smit, N., \& Morgan, R. M.
}

\begin{abstract}
There has been an increased engagement by researchers in understanding the decision-making processes that occur within forensic science. There is a rapidly growing evidence base underpinning our understanding of decision-making and human factors and this body of work is the foundation for achieving truly improved decision-making in forensic science. Such an endeavour is necessary to minimise the misinterpretation of scientific evidence and maximise the effectiveness of crime reconstruction approaches and their application within the criminal justice system. This paper proposes and outlines a novel six phased approach for how a broadening and deepening knowledge of decision-making in forensic science can be articulated and incorporated into the spheres of research, practice, education, and policy making within forensic science specifically, and the criminal justice system more generally. Phases 1 and 2 set out the importance of systematic examination of the decisions which play a role throughout forensic reconstruction and legal processes. Phase 3 focuses on how these decisions can, and should, be studied to understand the underlying mechanisms and contribute to reducing the occurrence of misleading decisions. Phase 4 highlights the ways in which the results and implications of this research should be communicated to the forensic community and wider criminal justice system. Lastly, the way in which the forensic science domain can move forwards in managing the challenges of human decision-making and create and embed a culture of acceptance and transparency in research, practice and education (learning and training) are presented in phases 5 and 6 . A consideration of all 6 connected phases offers a pathway for a holistic approach to improving the transparency and reproducibility of decision making within forensic science.
\end{abstract}

\section{Introduction}

A number of high profile cases (including those of Mayfield [1], McKie [2], and Knox [3]), government statements [4,5,6], popular documentaries [7], and news articles [8,9], have demonstrated the issues of forensic science evidence interpretation, and highlighted the potentially severe consequences of the misinterpretation of forensic science evidence to the forensic science community and general public. As a result, lay audiences have been increasingly confronted with the complex nature of criminal investigations and the interpretation of forensic science evidence within them, in addition to gaining an increased awareness of the potential for miscarriages of justice to occur. Whilst the misinterpretation of forensic science evidence has been newsworthy in mainstream media [9], it has also caused forensic scientists to acknowledge the necessity of a fundamental stepwise change [10]. Since the momentous report from the National Academy of Science in 2009 [11] issues of interpretation and concerns related to the reliability of forensic science evidence have frequently been raised in reports [12] and academic publications [13]. Indeed, almost a decade later, the same concerns and warnings are included in a broad range of publications spanning government reports (e.g. PCAST in 2016 [5] and House of Lords in 2019 [14]) the published academic literature $[15,16,17]$, and popular media.

However, within both the lay and forensic science communities there remains a tendency to blame quality standard failures in processes, or 'bad apple' forensic scientists for 
making erroneous decisions. There is then an assumption that removing the 'bad apples' or improving processes, will ensure the reliability of all of the 'fruits' of forensic science $[18,19]$. However, all human decision-makers, due to the very nature of human decision-making, are susceptible to intrinsic and extrinsic factors that can impact the decisions that are made [20]. When the inherent subjectivity of decision making is acknowledged, the importance of transparency in how decisions are reached becomes crucial [21]. It is then possible to begin to tackle 'bad apple' decisions, but also increase our understanding of decision-making in forensic science and crime reconstructions in order to provide increasingly transparent conclusions, and thereby increase the reliability of those interpretations. Embracing a dialogue between all the actors and institutions within the forensic science community is a fundamental step toward an open exploration of decision-making within the forensic science process. To ensure the integrity, transparency and reliability of forensic science evidence it is necessary to determine where issues exist, increase our understanding of the human interpretation processes involved, and then find ways to improve the transparency of decision-making processes.

In recent years, some forensic decision-making processes have been empirically investigated. Research in this area has tended to be specifically focused on cognitive biases and human interpretation issues, pioneered by several scholars [22], and, in particular, Dror $[23,24,25,26,27,28,29,30]$, whose research into the effects of cognitive bias, whilst initially controversial, has led to an increase of related research in a number of forensic science disciplines including DNA [31], fingerprints [27], blood pattern analysis [32,33], forensic odontology [34], forensic anthropology [35,36], handwriting analysis [37], ballistics [38], footwear analysis [39], and forensic entomology [40]. Indeed 'bias' has become something of a buzz word within forensic science research, conferences, and meetings, emerging as a distinct and increasingly recognised field of interest in forensic science, and becoming a motivational factor for organizational change $[24,41,42]$.

Some have argued that a disproportionate level of attention has been dedicated to subjective decision-making. It is argued that this preoccupation is preventing the forensic science domain from focusing on increasing the objectivity with which forensic science evidence can be interpreted, through a better understanding of the traces themselves [43] by, for example, carrying out empirical studies aimed at understanding the persistence and transferability of traces [44,45]. Others have responded by arguing that there is not, in fact, an overrepresentation of research into the factors that affect decision-making within forensic science, and that research establishing the existence and mitigation of cognitive bias, the impact of context, and the more objective use of trace evidence need not be mutually exclusive [46,47]. In the light of this, Buckleton et al. [48] use the illustration of the 'human machine', clarifying that there is not an argument to do away with the notion of subjective human decision-making within forensic science, rather that there is much that can be done to aid this process, using an empirical knowledge base, and an appropriate forensic science evidence base. Whilst the challenges in human decision-making have been increasingly documented, it is important to acknowledge that there are also great strengths in the capability of humans to make nuanced, context sensitive and complex decisions which need to be retained if we are to be engaged in the scientific endeavour of forensic reconstruction [49].

There has been increasing recognition of empirical studies that can contribute to an evidence based approach to the interpretation of forensic science evidence [50,51,52,53]. It has been asserted that empirical research, rather than an overreliance on training and experience, must become the central method by which assertions are justified [52], along with problem solving approaches that take into account the context of each case $[54,55,56]$. Notably, the 2016 
PCAST report [5] and the UK Forensic Science Regulator report [57] highlighted that forensic practitioners cannot rely on experience and extensive casework as a substitute for empirical studies of scientific validity. It is important not to create a dichotomy between empirical data evidence bases, and expertise and training, with calls for forensic science to engage with reconstruction approaches that include both forms of knowledge, but in a clear and transparent way [47]. Both empirical evidence bases and more tacit forms of knowledge that form expertise need to be harnessed to address the complex challenge of reliable interpretation of forensic science evidence given the nature of forensic reconstruction [21].

The production of empirical data that can contribute to an evidence base for forensic reconstruction that incorporates the intrinsic aspect of human decision-making has been aided by researchers who have begun to look beyond cognitive bias within forensic science. A consideration of judgment and decision theories $[58,59,60]$, while acknowledging the breadth and complexity of human decision-making $[61,62,63,64]$ offers valuable insights for the development of understanding the psychological processes behind the decisions being made in forensic science. However, we argue that there is a need for a more structured, inclusive, and sustainable approach to improve our understanding of decision-making within forensic science, and to aid the transparency of the conclusions that are reached in the interpretation of forensic science evidence. We present here a dynamic six-phased model (Figure 1), that addresses the critical component of human decision-making in holistic forensic reconstructions (as outlined in component 4 of the FORTE model [21]). The model outlines what is needed to achieve improved decision-making in forensic science for transparent, reproducible and robust crime reconstructions:

Phase 1: Mapping of the decisions that are made throughout the forensic process from crime scene to court.

Phase 2: Consideration of the role and interdependencies of forensic science decisions within the wider criminal justice system

Phase 3: Applying established empirical knowledge from other domains into forensic science judgment and decision-making research,

Phase 4: $\quad$ Suitable communication and dissemination of findings from decision-making research within the forensic community and the wider CJS,

Phase 5: Managing the risk of misinterpretation

Phase 6: Embedding the inclusion of decision-making as part of the forensic science process through bottom-up education and training. 


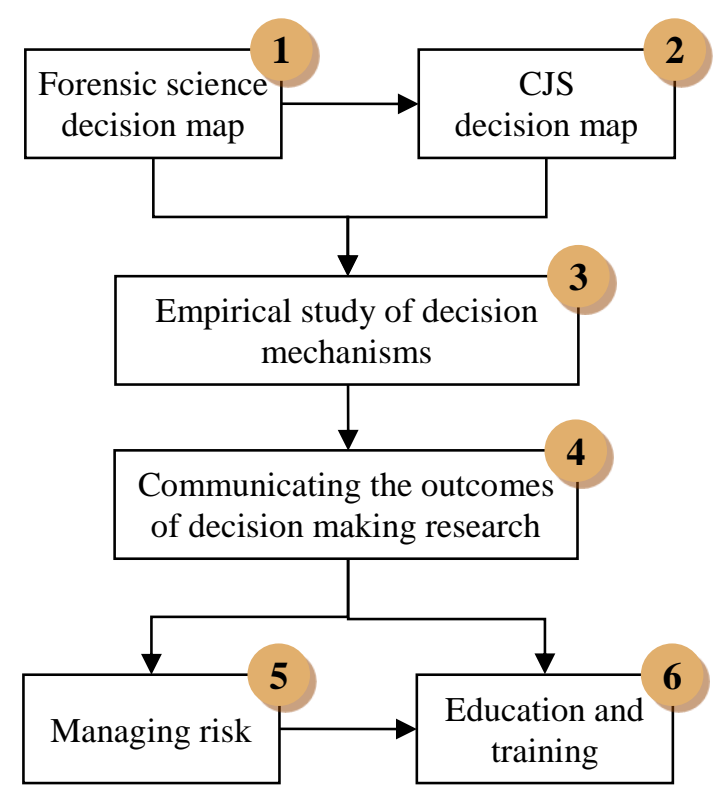

Figure 1: an overview of the proposed six-phased approach to improved decision-making within forensic science

Phase 1: A structured examination of forensic science decisions from crime scene to court

In order to fully understand and improve the reliability of the outcomes of the entire forensic science process (the collection, analysis, interpretation, and presentation of evidence as set out in Figure 2), it is important to acknowledge, investigate and understand each decision that is made both individually and interdependently. Forensic science procedures are made up of a number of decisions, many of which are not traditionally seen as being interpretative in nature. However, the outcome of these decisions may significantly influence interpretations that are made at later stages. For example, deciding upon an evidence recovery strategy at a crime scene may sometimes be influenced by what information examiners at the crime scene have been exposed to, be this from the call room, the CSI log, the investigating officer, or communication with the victim at the scene [65]. It is not always simple and self-evident what information is relevant and irrelevant in order to decide what to prioritise. This has the potential to create interpretive difficulties at a later stage if the decisions about what to collect at the crime scene have been influenced by misleading information or irrelevant context $[36,66]$. Similarly, decisions made at the crime scene or laboratory to process certain finger marks rather than others have the potential to be crucial in the interpretation and subsequent intelligence gathering stages [67]. Thus the recovery of certain traces at the scene, or from crime scene evidence, can have an impact upon the possibility of subsequent analysis and/or interpretation.

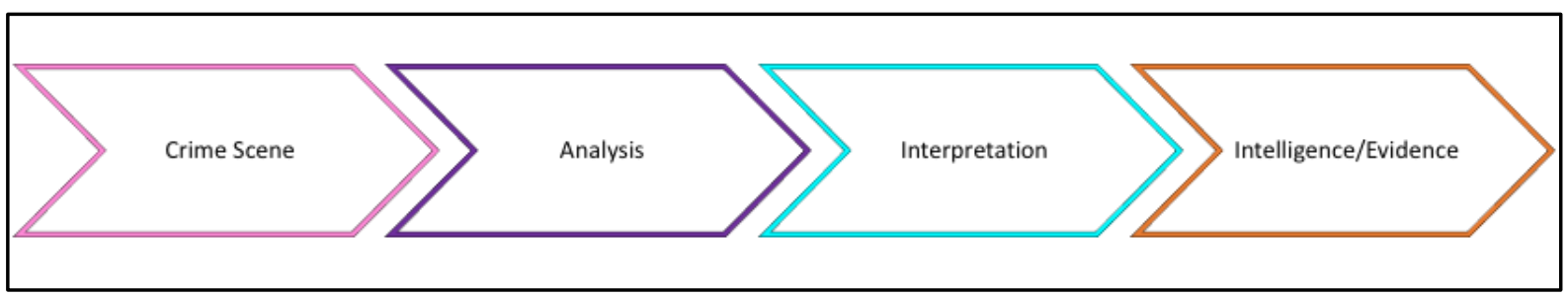

Figure 2: The forensic science process (adapted from Morgan 2018 [68]) 
Methodologies from the published literature in ergonomics is beneficial to ensure that the complexities of the human factors associated with the forensic science process are comprehensively recognised. The determination of points at which decisions are made should be based on more than just a standard operating procedure or reported process. Rather, this information must be gleaned from observations of processes in action within real world environments, so as to establish the 'hidden' decisions, judgements, and interpretations, and to establish the interactions between the person, the environment, and the technology required to meet each goal of the practitioner. The use of Hierarchical Task Analysis [69,70] allows goals to be broken down into smaller goals and plans, enabling complex processes to be described as a series of hierarchical simpler processes, while Cognitive Task Analysis [71] can be used to establish the cognitive skills required to reach a goal. Considering forensic science processes and the human and cognitive interactions with these processes in this structured way can enable a comprehensive understanding of the requirements placed upon the human practitioner (beneficial in training and learning [70], as discussed in Phase 5), and can help to clearly illustrate 'hidden' decisions, judgements and interpretations within the forensic science process. Such approaches have been used to consider aspects of teamwork and performance in crime scene investigations [72].

Figure 2 depicts the interconnectedness within the forensic science process and therefore the critical impact that decision-making has at each stage. It is also clear that decisions at each stage of the process can influence subsequent processes and decisions. It is therefore important to consider the whole process (from crime scene to court) and it is crucial that the capabilities, requirements and thresholds of each dependent stakeholder are acknowledged by each decision maker. Additionally, such considerations must be made within a wider context than the forensic science process, as described in Phase 2, and depicted in Figure 3.

\section{Phase 2: A structured examination of the wider decision ecology of the Criminal Justice System}

Following an acknowledgment of the interlinking and complex web of decisions being made within the forensic science process, there is a need to recognize that forensic science sits within the wider ecology of the criminal justice system (CJS) [47,73], in which wider investigative and legal decisions are made (see Figure 3). While stakeholders within policing and the court system may be making key simultaneous and interdependent decisions, it is important to acknowledge that key decisions are also made by professional and regulatory bodies, for example, UKAS and the Forensic Science Regulator in the UK, as well as international working groups such as European Network of Forensic Science (ENFSI) and Organisation of Scientific Area Committees for Forensic Science (OSAC), which may impact upon the forensic science process. Similarly, education and training institutes continue to influence the way that forensic science moves forward (as outlined in Phase 6). 


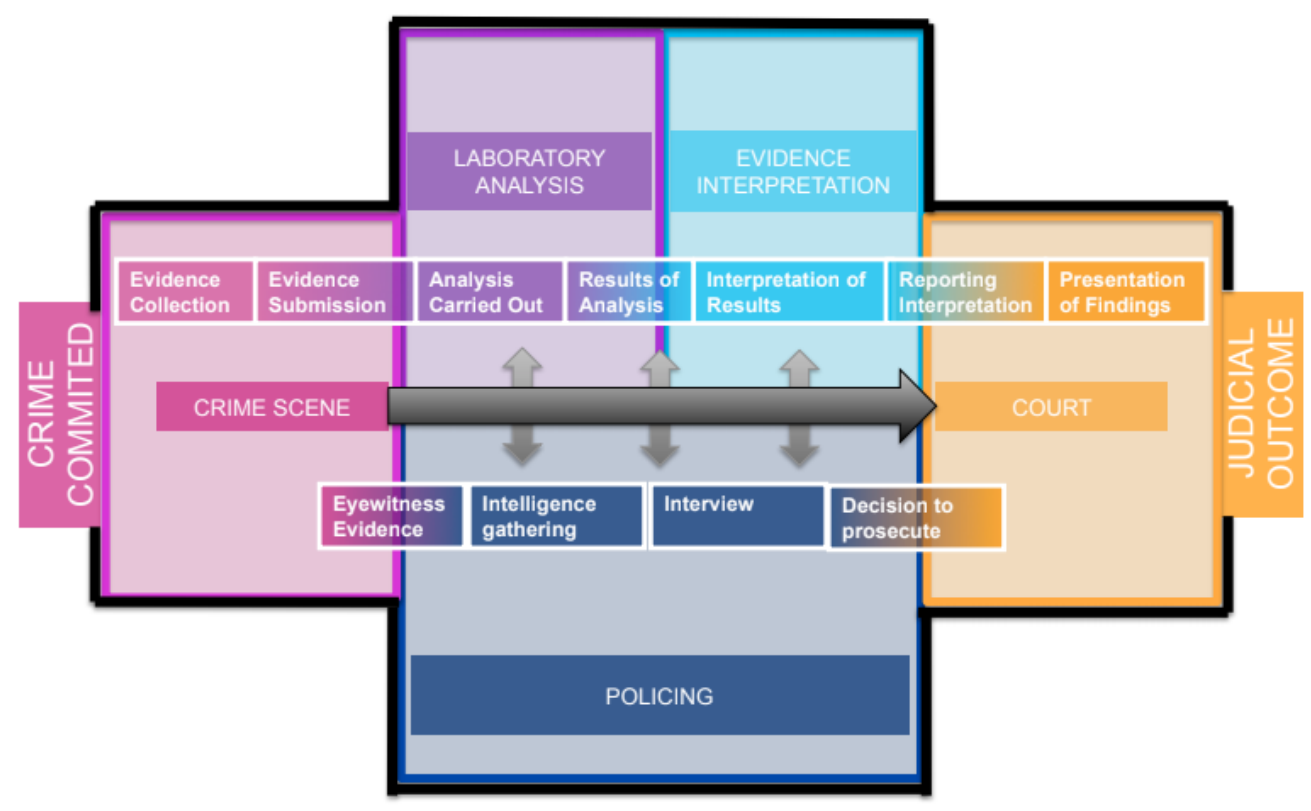

Figure 3: an illustration of the interdependent phases with their own associated decisions, within the forensic, investigative policing, and legal fields (Morgan et al., 2018 [74])

Thus, by virtue of the complex nature of decision-making in the criminal justice system, it is not sufficient to solely consider the decisions made by the forensic examiner when aiming to maximize the effectiveness of these decisions. Rather, the interactions and impact of a decision process should be considered within a wider context of their interactions with all stakeholders in the CJS (as summarised in Figure 3), in order to effectively, transparently, and reliably convey the weight of the forensic evidence within a case and ensure the value of the forensic science process. A failure to acknowledge and respond to the interlinking nature of stakeholders within the CJS could lead to an inappropriate use of evidence in a court or intelligence setting. For example, evidence disclosed to the police as a result of one isolated piece of forensic science analysis could begin to suggest a particular scenario, which could lead to tunnel vision within the police investigation due to the high motivation to identify and apprehend a suspect [75,76]. Conversely, the opinion of the police (which could also potentially be led by tunnel vision [75,77], cascade bias (the impact of contextual information at one stage in the reconstruction process impacting decisions being made at a later stage) and snowball bias (when a number of pieces of contextual information interact and have an increasing 'snowballing' impact on a decision that is made) [66], driven by other aspects of the investigation $[78,79]$ ) could impact upon the communication strategy of the police to forensic scientists. For example, when dealing with ambiguous evidence from a complex crime scene, a scenario could occur where the police and/or the prosecution have a strong belief of the guilt of a suspect. In such a scenario it is possible that the forensic scientist might be unconsciously steered towards a certain decision outcome, leading, in some cases, to an overestimation of the analysis [80]. This may be compounded if the forensic scientist is, as is commonly the case, employed by the prosecution [76].

Thus, each stakeholder needs to have a greater understanding of the role, requirements, capabilities, and limitations of the work of other stakeholders within the CJS. If, for example, police officers are not aware of the true probative value or discriminatory power stated in the results of a forensic examination, they may either put an understated or overstated weighting on this evidence when interviewing a suspect [81]. Being able to communicate how the 
meaning and weight of a conclusion has been reached, and explain any limitations of the outcome of the analysis and interpretations made is crucial to ensure the appropriate use of such evidence throughout the investigation. It is also possible to argue that having some understanding of how a result from the analysis of a forensic trace may contribute to an investigation could allow the forensic scientist to provide this result in the most appropriate and usable format.

In addition to ensuring that the potential of forensic science evidence is maximized in relation to evaluating source and activity level hypotheses, an awareness of the roles and processes of each key stakeholder is crucial in order to maximize timeliness of intelligence within an investigation. Recent approaches to enabling the rapid communication of indicative (as opposed to conclusive) forensic findings such as the use of Streamlined Forensic Reporting (SFR) within fingerprint comparison, have ensured that evidence can be utilized to provide swift provisional intelligence within an investigation [82]. The introduction of such processes has helped foster a mind-set in which forensic science becomes a part of the police investigation, leading to a scientific grounding to the direction of the investigation, as opposed to solely being a mechanism for providing the evidence for the propositions of the investigative team. Thus, it is crucial that investigators are aware of the limitations of the SFR results with which they are provided. If these results are an initial indication of the outcome of an interpretation but have not been through the entirety of a validated process in place to ensure the robustness of that interpretation (including aspects such as blind verification), then this should be clearly communicated to the investigative team, informing their own communication in relation to the weight of the evidence. This being the case, it is more important than ever that scientists and investigators are aware of their own role and that of other actors within the system in order to maximize the value and reliability of all intelligence and/or evidence. Additionally, the outcome of decisions made by regulatory and training stakeholders (which, in the UK, include reports such as the codes of practice issued by the Forensic Science Regulator, the components of mandatory UKAS accreditation , and the scope of training provided [83]) have the potential to impact upon the processes and information available for forensic decisionmaking, and so the breadth, and depth of this evidence base and its influences within the network also needs to be considered.

Given that the ultimate decision to utilize forensic evidence for the purpose of legal truth-finding lies within the judicial system, a better understanding of the interdependent inferences and underlying uncertainties of decisions made regarding forensic science evidence is clearly critical. This requires, on the one hand, better communication and understanding of the meaning and limitations (including the validity of methods) of the decisions made throughout the process illustrated in Figure 3, in order to allow the Trier-of-fact to make a transparent, reproducible as well as robust decisions [84]. Given that forensic reconstruction approaches necessarily have to incorporate an understanding of a variety of activities that have taken place in a complex real world environment, uncertainty must be acknowledged to be inherent in any forensic reconstruction approach. Decision-making leading to the interpretation of what forensic science evidence means in a given scenario will therefore always be carried out with intrinsic uncertainty caused by missing information and inherent limitations of reconstruction methods $([21,47,85]$. Therefore, it is not only the judicial system that can act as a gatekeeper to ensure reliable evidence is admitted, but forensic scientists and investigative teams should also be providing a transparent and critical (yet helpful) presentation of the value of the evidence in the light of the proposed hypotheses [86]. 
To date, the requirements of both the legal and scientific domains have been addressed by developing the evidence base behind the behaviour of forensic traces through empirical research in many different fields within forensic science based upon the abundance of properties, the effects of evidence dynamics, the processes affecting collection and analysis methods, and by developing methods to assist in drawing justifiable and transparent inferences $[87,86]$. However, it is crucial to also identify each decision, and the interactions of that decision with other decisions made, the stakeholders in the process, along with this evidence base, at each stage from crime scene to court (Figure 3), Methodologies from the ergonomics and human factors literature $[69,70,71]$ can be of benefit in achieving this aim, as set out in Phase 1. It is also important that the mechanisms behind each of these decisions are better understood in order to maximize the reliability, efficiency, and validity of inferences and conclusions provided to investigators and to the court, as explored in Phase 3.

\section{Phase 3: Applying judgement and decision-making/psychological theory to empirical research within forensic science}

Once the decisions and interpretations, and their interactions, within the forensic and wider criminal justice process have been identified it is crucial to understand the mechanisms of decision-making within this forensic context. Each decision can be considered in terms of the desired outcome (how success can be measured), the intrinsic factors influencing the outcome of the decision and the extrinsic factors that may have an influence on the decision-making process and outcome [89]. Each of these aspects needs to be explored in order to be able to provide a robust evidence base to support transparent and reliable forensic decision-making. This evidence base must be relevant to the operational reality of forensic science practice through ecologically valid empirical study, rather than a simple transfer of findings from the judgement and decision-making domain into forensic reconstruction approaches, given the complexities of forensic decisions within existing policies and procedures [90,91,92].

Given the complexity of understanding the decision-making mechanisms within forensic reconstruction approaches there is the need for further research to address the following gaps:

\section{a) Not all forensic science domains have empirical data that addresses decision-making}

Research which has looked to investigate and empirically assess the effectiveness of decision-making within forensic science has been carried out in a number of forensic domains, but has been focussed within the fields of identification such as fingerprinting [27,93] and DNA analysis [94]. There is, therefore, a paucity of research within many other forensic domains [95], paralleled by a reluctance to accept that the inherent limitations of the subjective nature of human decision-making can lead to misinterpretations of the meaning of evidence in specific contexts. Whilst it is clear that there is broad transferability of research findings that address decision-making in forensic science, it is also crucial that empirical research addresses all domains of forensic science, as the decisions, processes, procedures, and circumstances will be context sensitive and vary to some extent between individual domains.

\section{b) Empirical examination of decision-making has lacked a joined-up approach from crime scene to court}

To date, not all stages of the forensic science process (Figure 2) have been addressed by published empirical studies in relation to decision-making. Published research has, instead, tended to focus upon the more traditionally considered interpretative aspects of forensic 
science occurring at the analysis stages of the process, primarily the comparison between a crime scene trace and suspect sample $[96,97]$. This focused approach has led to a paucity of research addressing the processes involved in, and the efficiency of, decisions made at earlier (and, indeed, later) stages of the forensic science process. A particular example is the empirical study of decision-making at the crime scene. There are many crucial judgements and decisions made at the crime scene, for example, how to approach a search of the scene, or how to assess which items to recover as exhibits as part of a strategic approach to intelligence gathering [56]. These decisions are often made under the highly pressured and emotive conditions which are considered to be potential fuels for subconscious influences in decision-making [98]. Given the environment in which these decisions are made and the potential for snowball effect and cascade bias within decisionmaking later in the forensic reconstruction process [66], it is important that empirical studies are extended to cover a wider remit of forensic reconstruction decisions, encompassing the whole forensic reconstruction process [21]. Equally, the impact of the presentation of findings of the forensic science process on the judgements, decisions, and interpretations of the investigative team, key stakeholders within the legal domain, and judges and juries should be comprehensively explored, both in terms of the existing mechanisms of reporting forensic outcomes and also in relation to the application of new techniques and technology (for example the use of 3D technology [99] or virtual reality reconstruction within the courtroom $[100,101]$, or the application of novel approaches to data collection [102], analysis [103], or interpretation [104,105]). The breadth of knowledge within the jury studies literature $[62,106,107,108,109]$ should be considered in application to the context specific nature of forensic science evidence, acknowledging that the specific nature of the evidence presented in each case will be different. The comprehensive mapping of decisions and interpretations as described in phases 1 and 2 will highlight these 'hidden decisions' throughout the forensic science process and should direct the focus of empirical study.

\section{c) Establishing the presence of cognitive bias has become the focus of decision-making research}

The body of knowledge concerning judgement and decision-making and human factors is broad, encompassing a wide range of theories, and addressing a broad range of attributes, going far beyond the consideration of cognitive bias alone which has become a focus within decision-making within forensic science [95]. Indeed, there are many aspects of psychological and human factors theory that have been applied to other domains that involve human expertise (such as medicine [110] or aviation [111]), or have been used by psychologists to explore or explain human decisions. Edmond et al. [112] presented a number of such theories from human perception, memory, expertise, decision-making, communication and feedback in relation to the forensic science process so as to highlight the potential application of these theories within forensic science, encouraging forensic practitioners to engage with such research in order to maximise the outcome of their forensic interpretations. Examples included areas of psychological study such as the fallibility of perception and memory, a tendency for overconfidence, and the specific nature and vulnerabilities of expertise [112]. Indeed, there are many areas in which forensic science can learn from the broad range of literature on human factors originating from many different domains of study. There is potential (and need) to consider the application of the empirical evidence that addresses the different aspects of research into human performance, human factors, and decision-making to the specific interpretations and decisions made throughout the forensic science process. For example, there are theories of human decision- 
making that suggest that the environment in which a comparative judgement is made and working memory are important in that judgement $[113,114,115,116]$, the language of signal detection theory [117] may be helpful to discuss the detection and quality assessment of forensic traces [118], the anchoring heuristic [119] may, perhaps, play a role in forensic interpretations that involve numerical values, there may be merit in the application of the principles and techniques of the cognitive interview [120] in gaining accurate recall of events at the crime scene, and considering distributed cognition [66,72] may be valuable when there are interconnected decisions and interpretations throughout the forensic science process.. It is important, however, that novel empirical research tests hypotheses around the application of these existing theories within a range of ecologically valid forensic contexts in order to ensure that the outcomes and findings are representative of real world forensic practice as the real world environment is very different from what can be replicated in a psychology laboratory setting. This approach provides an opportunity to expose actual decision-specific vulnerabilities, mitigate negative effects and increase performance, and identify and accept, through empirical evidence, the inherent limitations of the 'human machine' [46] to ensure transparency, proportionality and robustness in forensic decisionmaking.

Appreciating the need for a comprehensive, interdisciplinary approach to the understanding of decision-making and interpretations within forensic science provides a promising pathway to be able to increase the transparency and effectiveness of current decisions throughout the forensic science process.

Therefore, collating the findings and underlying conceptual frameworks in empirical studies provides the opportunity to improve the evidence base, accuracy, and transparency, of forensic reconstruction inferences. A key precedent to achieving this will be the approaches developed to effectively communicate and disseminate the findings of this research into the forensic chain and the wider criminal justice system [86], as will be discussed in Phase 4.

\section{Phase 4: Improving the communication and dissemination of novel decision-making research}

It was not until recently that stakeholders with the power to influence policies have presented the findings of significant decision-making research in their reports and urged their importance in forensic practice $[121,122]$. In addition, the development of 'cognitive forensics' as a distinct field within forensic science research at international conferences and meetings has enabled the communication of research findings that address the influences on decision-making within the forensic reconstruction process. However, communicating the findings of specific empirical research on the influences on decision-making remains problematic, particularly outside of an academic setting, in the following ways:

\section{a) Bridging the gap between psychological theories and forensic specialists}

Whilst research into forensic decision-making needs to draw more heavily upon a wide range of psychological approaches and theories, the findings of any such research also needs to be accessible to the forensic scientist and the environment within which the forensic reconstruction is carried out. This means foremost that the results need to be clearly accessible, visible, and explained in appropriate terminology and language so that the importance of the findings are recognised, the value of the findings is clear and the practical implications provided in a manner that is sensitive to the different contexts and drivers of key stakeholders [21,47]. 
Research that addresses the influences on decision-making, including the research that identifies as 'cognitive forensics' should, perhaps, be more successfully integrated within existing forensic science domains, as opposed to being thought of as a separate entity. It is important to establish a balance between developing a specialist area of decision-making in forensic science, whilst also successfully integrating it into the different forensic fields alongside, for example, research on analytical techniques, transfer and persistence studies, population studies, and statistical interpretation methods. Equally, researchers addressing decision-making in forensic science need to incorporate the requirements of the forensic practitioner into the research questions and research design to ensure that the findings are casework informed and implementable. Integrating a consideration of decision-making across the whole forensic science process (Figure 3) offers the opportunity to identify common issues across different forensic domains as well as specific issues that are relevant to a specific domain or subset of domains. It is important to acknowledge that decisionmaking studies will be most effective when they are based upon actual current processes which have been as fully understood as possible by the researcher through established ecologically valid methodologies (as set out in Phase 1), rather than solely through consultation of reported processes and Standard Operating Procedures.

\section{b) Transparent communication of research findings}

Empirical studies within forensic science and decision-making need to be peer reviewed and accessible to the scientific community. However, the publication of research which exposes issues within forensic science processes prior to the adaptation of a successful solution is understandably problematic. While publication and dissemination is crucial to enable the development of further research and applied solutions from other domains, it can also create vulnerabilities in the integrity of past and current processes. There is a growing acknowledgement of the necessity of such research, but for this type of research to happen to the extent that is necessary there is arguably the need to foster an environment where the value of this type of research is acknowledged and enabled. This will require a commitment to change in a holistic manner that incorporates all the actors, institutions and stakeholders in the forensic science domain (Figure 3).

\section{c) Avoiding the communication of research findings as performance data}

It is paramount that there is a differentiation between communicating research into decision-making in the forensic science process as individual performance data, in order to avoid a 'bad apple' [18] blame culture which has the potential to obfuscate the critical underlying issues. Although decision-making research is crucially based upon studying participants undertaking every-day tasks within the forensic reconstruction process, the nature of the research design must account for the possibilities of drawing conclusions beyond individual participants. The need for a move towards identifying and managing the possibilities of misinterpretations of evidence is outlined in Phase 5.

\section{Phase $5 \quad$ Managing the risk of misinterpretation}

The generic use of the term 'error' is problematic in forensic science. The terminology of 'error' was first widely used within the US as a result of the introduction of the Daubert Standard for admissibility of evidence [123] and the later publication of the National Academy of Sciences Report [11]. Equally, in the UK, the need for quality standards and adhesion to Codes of Practice and Conduct in order to prevent error has been recently communicated by 
the UK Forensic Science Regulator [83,122]. However, the communication surrounding errors within forensic science can lead to misunderstandings and misinterpretations, due, in part, to the role of both tacit and explicit forms of knowledge within the forensic science process [47], confusion concerning the different types of errors that can occur [124], and, therefore, the misapplication of the terminology of 'error' and the assumption that it is always indicative of blame.

Figure 4 sets out the interaction of the explicit tacit knowledge continuum as it relates to key parts of forensic science (from Morgan 2017b, [47]) and the existing definitions of error within forensic science (from Christensen et al., 2014 [124]). It is clear that there is a wide spectrum of the interplay between knowledge type and error type.

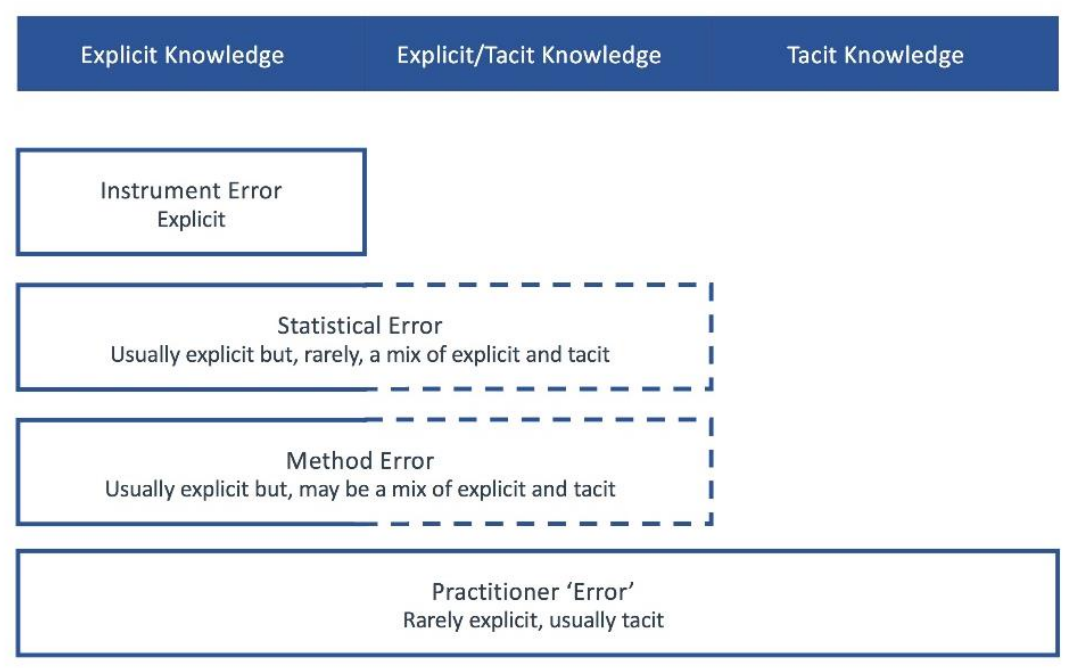

Figure 4 - the relationship between explicit (negligence, incompetence, sabotage) and tacit (judgement calls, experience, heuristics, routines) knowledge and error types within forensic reconstruction

Consideration of the psychological literature in relation to errors reveals a difference in approach and mentality around the discussion of errors in an organisational setting. Frese and Keith [125] discuss the tendency for a negative mind-set and language around error making, which is indeed, commonly referred to within the forensic science literature $[19,126]$. Frese et al. [127] first introduced the key concept of error management to the dialogue around error. They clearly distinguish between two organisational approaches to dealing with error: error prevention and error management. It is argued that all errors cannot be prevented due to their ubiquitous nature [125], partly due to the tendency of human cognition to be prone to heuristic processes [128]. Individuals and organisations, however, have a tendency to view error making in a negative way and as an indicator of poor performance or negligence [129], and so try to prevent these errors from occurring [130]. Error management is described as "effectively dealing with errors after they have occurred with the goal of minimising negative, and maximising positive, error consequences", as opposed to the view that all errors can be prevented [125]. Such an approach acknowledges the inherent nature of errors and looks to learn and innovate as a result of them through an open and honest dialogue. Processes in error management primarily involve the detection of errors and the reduction or avoidance of the negative consequences of this error. 
A similarly structured approach is taken to the consideration of error within the aviation industry, where five perspectives are taken on the nature and cause of human error; (a) a cognitive perspective, (b) an ergonomics and systems design perspective, (c) a medical perspective, (d) a psychosocial perspective, and (e) an organisational perspective [131]. Whilst there is benefit in the consideration of each of these areas in relation to decision-making within the forensic science process, it is the organisational approach that is often preferred within the aviation industry because it views human error as something to be managed within the context of risk [131].

Given the complex and varied nature of knowledge with the forensic science process [21], the breadth of error types [124], and the negative connotations of 'error' terminology within the forensic science community $[19,126]$, alongside the inherent nature of human error [128] and need to expose and manage it [125], a new dialogue may be beneficial. Rather than using the terminology of 'error' it may be preferable to, instead, discuss the risky nature of forensic science, enabling dialogue around management of this risk ('the impact of uncertainty on objectives' [132]) that is focussed around the forensic science process rather than attributing blame to the individual.

The objective of the forensic science process can be considered, at a holistic level, to be an accurate forensic crime reconstruction, applying science to determine the true activities of a crime event [21,133]. Achieving this holistic objective requires a series of 'micro' objectives throughout the forensic science process, at the explicit level (adhering to process), and at the tacit level (making the correct decision or appropriate decision at each stage of the process). There are many uncertainties associated with the outcomes at both of these levels. At a holistic level there is usually the absence of a reliable known ground truth to which to compare a forensic reconstruction, so there is inherent uncertainty that an accurate representation of events has been made. The lack of a comprehensive evidence base in relation to the behaviour of forensic trace evidence [134]) introduces uncertainty at specific stages of the forensic science process, and, equally, the lack of a comprehensive understanding of the human examiner, as discussed in Phase 3, introduces a level of uncertainty to interpretations. Indeed, more complex processes, or those involving complex chains of activities and decisions will lead to a higher level of uncertainty. The level of interpretation and tacit knowledge required as part of a process will affect the level of uncertainty, and thus risk. For example, toxicological analysis based primarily on explicit knowledge may be low in uncertainty as calibration and standard operating procedures can be employed, and any deviation can be identified and measured, reducing the risk. The comparison of footwear evidence, however, relies on tacit knowledge and expertise (that which is more difficult to codify [47]), thereby increasing the uncertainty and thus the risk. Knowing about the existence of uncertainties means that we can include these in our reasoning, increasing the transparency of interpretations and reducing the risk of misinterpretation. A key consideration is that, whilst we may be aware of some of the uncertainties inherent in forensic science processes, there are also those uncertainties that we are unable to codify, either because we cannot accurately predict these, or because we do not know that they exist. Knowing where uncertainty lies means that we can build up a picture of the risk associated with a process and determine the acceptable level of that risk. Thus, research into the human factors associated with forensic processes is key to codifying some of these uncertainties and communicating them effectively to reduce the risk of misinterpretation at each stage of the forensic science process.

The challenge for the forensic science community is acknowledging these uncertainties and determining what level of risk is acceptable and, indeed, what level of risk can be effectively communicated when it comes to presenting the meaning of the evidence. The ethos of risk management rather than prevention is key here so as to ensure that there is transparency and 
reproducibility in the way inferences are made and conclusions are drawn, and to ensure that the forensic community is able to learn and innovate.

A good example of the management (as opposed to prevention) of risk comes from the domain of fingermark visualisation. The Fingermark Visualisation Manual (FVM) [135] produced by the Home Office Defence Science and Technology Laboratory, provides recommendations as to the most effective fingermark visualisation techniques to apply according to the composition and condition of a given substrate from the crime scene. Those techniques that have been comprehensively validated following the recommended fingerprint visualisation techniques research methodology set out by Sears et al. [136], including laboratory based comparative studies and operational trials (thus reducing uncertainty) are provided as 'Category A' processes and are recommended for routine use. However, the manual also includes techniques and processes that are at earlier stages of development. These are supported by less validation studies, perhaps have not been trialled in case work, and so carry a greater level of uncertainty and thus risk. The FVM clearly makes a distinction between the category of technique so that practitioners can be aware of the risk involved. The lower category (more risky) techniques may be employed after other techniques have been attempted, or if there are no other options given the condition of the substrate from the scene. This provides a framework for practitioners to consider risk in their treatment selection decision-making and also in the interpretation of their findings, for example if no marks are produced through the use of a technique within a lower category of the manual there are more unknowns present, as this may be due to the fact that the technique has not been optimised rather than the fact that there were no latent marks present in the first place to visualise.

Challenges in the appropriate management of risk can be observed in relation to the accreditation of forensic processes to the UKAS standards of ISO 17025 and 17020 [83]. These are models of accreditation designed to accredit codified, or explicit, knowledge, however significant challenges and issues become clear when this same approach is applied to accredit the expertise of CSIs and fingerprint examiners which is founded in an interaction of tacit knowledge with explicit knowledge [47,49]. As a result, accreditation has the capacity to reduce the uncertainty in relation to the explicit knowledge and procedural aspects of the tasks undertaken, but cannot comprehensively consider the level of uncertainty associated with expertise. Thus accreditation does not holistically manage the risk as it does not account for the unknown uncertainty in the process [49].

Research into human factors as applied to the forensic science process, as outlined in Phase 3 can help to reduce the unknowns and reduce the amount of uncertainty. A cultural change is needed to ensure that the forensic community can adopt and operate with the notion of risk being inherent within the forensic science process so as to embrace human factors research which will, undoubtedly, lead to the uncovering of further uncertainties. It is only by being open to acknowledging the findings of human factors research that the forensic community can be comprehensively transparent about the strengths, weaknesses, and uncertainties of the processes used, thus being transparent about the risk involved, strengthening the reliability of forensic science evidence interpretation. Stepping away from a culture of blame and instead embracing a dialogue of risk, enables the forensic science community to openly explore decision-making within the forensic science process; determining where issues exist, increasing understanding of the human interpretation processes involved, and finding ways in which decision-making processes can be improved in order to ensure the integrity and reliably of forensic evidence.

\section{Phase 6 Fostering the inclusion of decision-making as part of the forensic science process through learning and training}


There has been some acknowledgement by researchers, policy makers, and regulators that solutions to the known effects of cognitive bias should be put in place $[24,42,97,137]$ and there has been a drive to inform practitioners of the dangers of cognitive bias. However, there needs to be a more holistic consideration of the human factors throughout the forensic science process and the ways in which learning and training can maximise the effectiveness of the human practitioner. Indeed, there is an argument for incorporating human factors at the heart of forensic science learning and training due to i) the ubiquitous nature of human factors and decision-making embedded throughout the forensic science process, ii) the intrinsic necessity to incorporate both explicit and tacit forms of knowledge in that process, and iii) the learner is human.

It is beneficial to consider the divide between learning and training in terms of the types of knowledge required of the forensic practitioner. As discussed in Phase 5 there is a combination of explicit (or codifiable) knowledge and tacit knowledge (or expertise) required throughout the forensic science process [47]. Training in a task can enable the development of specific skills required for explicit tasks such as following a standard operating procedure or using a new piece of software. However, acquiring and imparting tacit knowledge and the development of expertise is a more complex process. In relation to the approach that is needed where tacit knowledge and expertise is key, it is important to

i) determine all situations in which tacit knowledge is required for decision-making and making interpretations,

ii) have an evidence based understanding of the critical human factors involved in these situations,

iii) consider where this uncertainty is inherent and needs to be built into how findings are communicated (ie being clear what the 'known unknowns' and 'unknown unknowns' are),

iv) establish where there is uncertainty and where this uncertainty can be reduced through education (learning and training), and,

v) to consider the most effective mechanism for delivering the most appropriate education (ideally based upon the pedagogic literature and best practice from other domains that rely upon human expertise).

Thus the learning of a forensic practitioner should encompass both training that imparts the required explicit knowledge and skills needed to carry out specific tasks and procedures, as well as the learning required that enables and supports the development of tacit knowledge and expertise.

There is also a need to drive a cultural change in which human factors are recognised as an integral part of the forensic science process. Arguably, cultural changes only occur with both bottom-up and top-down approaches. There is a need for bottom-up changes, where decisionmaking theories are incorporated into research- and practice-led teaching at an early stage. This will foster a culture where future stakeholders within the forensic science domain will be equipped to be sensitive to incorporating how decisions are made, what variables may influence those decisions, how to combat any issues that may arise, and how to enhance performance in the judgment and decision-making taking place in forensic reconstructions [24,41].

There is still however a distinct lack of clarity regarding just how the body of knowledge on 
the application of decision theories within forensic science can be beneficial in the learning and training process. This is an important area to consider going forward. In particular creating environments where education approaches foster in students i) critical thinking skills, ii) a willingness to fail in order to identify solutions to challenges and refinements to existing approaches, iii) an interdisciplinary mind-set where common themes are identified and an ability to transfer ideas and approaches across domains in coherent and context sensitive ways is encouraged, iv) an ability to identify the unknowns, and develop approaches to creating new knowledge that addresses those gaps that are strategic for enhancing forensic reconstruction approaches. In so doing, as a community, we can foster a culture where the importance of the 'scientific endeavour' [133] in forensic reconstruction is cultivated.

Bottom-up approaches will also be critical to achieving the incorporation and awareness of human decision-making in robust and transparent forensic reconstructions. However, given the complex ecosystem within which forensic science is situated, a consideration of the role that top-down initiatives can play will also be critical for a holistic and wholesale approach that resonates with the whole forensic science process. Creating a true culture change where forensic science practice, research, policy, investigations and the courts are enabled and equipped to engage with forensic science evidence that is transparently articulated and appropriately presented at the different stages within the forensic science process, will be critical [47]. Only if the full spectrum of knowledge is valued, and a common language established to communicate uncertainty, will an environment be created that values holistic approaches to learning and training, and that can sustain and enable the collaborations that are needed across each domain within forensic science.

\section{Conclusion}

Although more research has been undertaken recently within forensic science that addresses the significance and impact of decisions made throughout the process from crime scene to court, we have argued that there is the need for a more structured and inclusive approach, and present a 6 phase model that suggests the key attributes that should be incorporated into a fuller understanding of decision making in forensic science reconstruction approaches. Because of the many interdependencies of the decisions made within the wider criminal justice system, improving the desired outcomes of decisions within forensic science and reducing the likelihood of misinterpretation starts with an improved understanding of the nature and significance of all the key decisions (phases 1 and 2). Empirical research clearly has an important role in understanding these decisions and in testing and applying a range of theories and approaches from the psychology domain (phase 3) to these decisions. Successfully communicating and disseminating this foundational understanding into the wider criminal justice system in order to facilitate operational improvements (phase 4) can then be considered and developed. The model highlights that, in order to fully incorporate theoretical knowledge of decision-making into practice, a culture of risk management (rather than a language of error prevention) needs to be embraced, and education, (learning and training) needs to target both explicit and tacit knowledge to enable a bottom up cultural change within an overarching environment that can sustain that change (phase 5 and 6).

Declarations of interest: none. 


\section{References}

[1] Office of the Inspector General. (2006). A review of the FBI's handling of the Brandon Mayfield Case.

[2] Fingerprint Inquiry. (2011). The Fingerprint Inquiry Scotland.

[3] S. M. Kassin, (2012) Why confessions trump innocence. The American Psychologist, 67(6) 431-45. https://doi.org/10.1037/a0028212

[4] FBI, (2015) FBI Testimony on microscopic hair analysis contained errors in at least 90 percent of cases in ongoing review https://www.fbi.gov/news/pressrel/press-releases/fbitestimony-on-microscopic-hair-analysis-contained-errors-in-at-least-90-percent-of-cases-inongoing-review,

[5] PCAST. (2016). Forensic Science in Criminal Courts: Ensuring Scientific Validity of Feature-Comparison Methods.

[6] Forensic Science Regulator (2017) Annual Report.

[7] Deo, A. Del, Demos, M., Nishimura, L., \& Ricciardi, L. (2015). Making a Murderer. United States: Netflix.

[8] Davis, N. (2017). DNA in the dock: how flawed techniques send innocent people to prison. The Guardian, pp. 1-5.

[9] Morgan, R. M. 2018a Forensic Science: the tip of the iceberg? The Guardian. Available at: https://www.theguardian.com/science/brain-flapping/2018/apr/19/forensic-science-the-tipof-the-iceberg

[10] Mnookin, J., L., (2018) The Uncertain Future of Forensic Science. UCLA School of Law, Public Law Research Paper No. 18-42. Available at SSRN:

https://ssrn.com/abstract $=3300354$

[11] National Research Council. (2009). Strengthening Forensic Science in the United States: a Path Forward. Washington D.C.

[12] The Law Commission. (2011). Expert Evidence in Criminal Proceedings in England and Wales. London.

[13] Bell, S., Sah, S., Albright, T., D., Gates Jr, S., J., Bonner Denton, M. \& Casadevall, A. (2018) A call for more science in forensic science, PNAS, 115 (18), 4541-4544.

http://www.pnas.org/content/pnas/early/2018/04/11/1712161115.full.pdf

[14] House of Lords Science and Technology Select Committee, Forensic Science and the criminal justice system: a blueprint for change. $3^{\text {rd }}$ Report of session 2017-2019 HL Paper 333 (2019) available at:

https://publications. parliament.uk/pa/ld201719/ldselect/ldsctech/333/333.pdf [last accessed 30th July 2019]

[15] Smit, N.M., Morgan, R. M., \& Lagnado, D. A. (2018). A systematic analysis of misleading evidence in unsafe rulings in England and Wales. Science \& Justice, 58(2), 128- 
137.

[16] Dror, I. E. (2018). Biases in Forensic Experts. Science, 360 (6386), 243. DOI:

$10.1126 /$ science.aat 8443

[17] LaPorte, G..(2017). Wrongful convictions and DNA exonerations: Understanding the role of forensic science. NIJ Journal, 279,

250705 https://www.nij.gov/journals/279/Pages/wrongful-convictions-and-dnaexonerations.aspx

[18] Bunkley, N. (2008). Detroit police lab is closed after audit finds serious errors in many cases. The New York Times.

[19] Thompson, W. C. (2010). Beyond bad apples: analyzing the role of forensic science in wrongful convictions. Southwestern University Law Review, 1, 971-994.

[20] Kassin, S. M., Dror, I. E., \& Kukucka, J. (2013). The forensic confirmation bias:

Problems, perspectives, and proposed solutions. Journal of Applied Research in Memory and Cognition, 2(1), 42-52. https://doi.org/10.1016/j.jarmac.2013.01.001

[21] Morgan, R. M. (2017a). Conceptualising forensic science and forensic reconstruction. Part I: A conceptual model. Science and Justice, 57(6), 455-459.

https://doi.org/10.1016/j.scijus.2017.06.002

[22] Found, B. (2014). Deciphering the human condition: the rise of cognitive forensics. Australian Journal of Forensic Sciences, 1-16. https://doi.org/10.1080/00450618.2014.965204

[23] Dror, I. E. (2011). The Paradox of Human expertise: why experts get it wrong. In N. Kapur (Ed.), The Paradoxical Brain (pp. 177-188). Cambridge.

[24] Dror, I. E. (2014). Practical Solutions to Cognitive and Human Factor Challenges in Forensic Science. Forensic Science Policy \& Management: An International Journal, 4(3-4), 105-113. https://doi.org/10.1080/19409044.2014.901437

[25] Dror, I. E. (2015). Cognitive neuroscience in forensic science: understanding and utulizing the human element. Philosophical Transactions of the Royal Society, 370(1674), 20140255.

[26] Dror, I. E., Champod, C., Langenburg, G., Charlton, D., Hunt, H., \& Rosenthal, R. (2011). Cognitive issues in fingerprint analysis: inter- and intra-expert consistency and the effect of a "target" comparison. Forensic Science International, 208(1-3), 10-7. https://doi.org/10.1016/j.forsciint.2010.10.013

[27] Dror, I. E., Charlton, D., \& Péron, A. E. (2006). Contextual information renders experts vulnerable to making erroneous identifications. Forensic Science International, 156(1), 74-8. https://doi.org/10.1016/j.forsciint.2005.10.017

[28] Dror, I. E., Wertheim, K., Fraser-Mackenzie, P., \& Walajtys, J. (2012). The impact of human-technology cooperation and distributed cognition in forensic science: biasing effects of AFIS contextual information on human experts. Journal of Forensic Sciences, 57(2), 34352. https://doi.org/10.1111/j.1556-4029.2011.02013.x

[29] Dror, I. E., \& Charlton, D. (2006). Why experts make errors. Journal of Forensic Identification, 56(4), 600.

[30] Dror, I. E., \& Cole, S. A. (2010). The vision in "blind" justice: expert perception, 
judgment, and visual cognition in forensic pattern recognition. Psychonomic Bulletin \& Review, 17(2), 161-167.

[31] Dror, I. E., \& Hampikian, G. (2011). Subjectivity and bias in forensic DNA mixture interpretation. Science \& Justice, 51(4), 204-8. https://doi.org/10.1016/j.scijus.2011.08.004

[32] Taylor, M. C., Laber, Kish, P., E., Owens, R. G., \& Osborne, N. K. P. (2016). Reliability assessment of current methods in bloodstain pattern analysis, Part 1: bloodstain patterns on rigid non-absorbant surfaces. Journal of Forensic Sciences, 60 (4), 922-927.

[33] Osborne, N. K. P., Taylor, M. C., \& Zajac, R. (2016). Exploring the role of contextual information in bloodstain pattern analysis: A qualitative approach. Forensic Science International, 260, 1-8. https://doi.org/10.1016/j.forsciint.2015.12.039

[34] Osborne, N. K. P., Woods, S., Kieser, J., \& Zajac, R. (2014). Does contextual information bias bitemark comparisons? Science \& Justice, 54(4), 267-73. https://doi.org/10.1016/j.scijus.2013.12.005

[35] Nakhaeizadeh, S., Dror, I. E., \& Morgan, R. M. (2014). Cognitive bias in forensic anthropology: visual assessment of skeletal remains is susceptible to confirmation bias. Science \& Justice, 54(3), 208-14. https://doi.org/10.1016/j.scijus.2013.11.003

[36] Nakhaeizadeh, S., Morgan, R. M., Rando, C. \& Dror, I. (2017). Cascading bias of initial exposure to information at the crime scene to the subsequent evaluation of skeletal remains. Journal of Forensic Sciences. 63. 10.1111/1556-4029.13569.

[37] Stoel, R. D., Dror, I. E., \& Miller, L. S. (2014). Bias among forensic document examiners: Still a need for procedural changes. Australian Journal of Forensic Sciences, 46, 91-97. https://doi.org/10.1080/00450618.2013.797026

[38] Kerstholt, J., Eikelboom, A., Dijkman, T., Stoel, R. D., Hermsen, R., \& van Leuven, B. (2010). Does suggestive information cause a confirmation bias in bullet comparisons?

Forensic Science International, 198(1-3), 138-142.

https://doi.org/10.1016/j.forsciint.2010.02.007

[39] Kerstholt, J. H., Paashuis, R., \& Sjerps, M. J. (2007). Shoe print examinations: Effects of expectation, complexity and experience. Forensic Science International, 165(1), 30-34. https://doi.org/10.1016/j.forsciint.2006.02.039

[40] Archer, M. S., \& Wallman, J. F. (2016). Context Effects in Forensic Entomology and Use of Sequential Unmasking in Casework. Journal of Forensic Sciences.

https://doi.org/10.1111/1556-4029.13139

[41] Dror, I. E. (2016). A Hierarchy of Expert Performance (HEP). Journal of Applied Research in Memory and Cognition, 5. https://doi.org/10.1016/j.jarmac.2016.03.001

[42] Dror, I. E., Thompson, W. C., Meissner, C. A., Kornfield, I., Krane, D., Saks, M. J., \& Risinger, M. (2015). Letter to the editor- context management toolbox: A linear sequential unmasking (LSU) approach for minimizing cognitive bias in forensic decision making. Journal of Forensic Sciences, 60, 1-2. https://doi.org/10.1111/1556-4029.12805

[43] Champod, C. (2014). Research focused mainly on bias will paralyse forensic science. Science \& Justice, 54(2), 107-109. https://doi.org/10.1016/j.scijus.2014.02.004

[44] Morgan, R. M., Allen, E., King, T., \& Bull, P. A. (2014). The spatial and temporal distribution of pollen in a room: Forensic implications. Science \& Justice, 54(1), 49-56. https://doi.org/10.1016/j.scijus.2013.03.005 
[45] Scott, K. R., Morgan, R. M., Jones, V. J., \& Cameron, N. G. (2014). The transferability of diatoms to clothing and the methods appropriate for their collection and analysis in forensic geoscience. Forensic Science International, 241, 127-137.

https://doi.org/10.1016/j.forsciint.2014.05.011

[46] Risinger, D. M., Thompson, W. C., Jamieson, A., Koppl, R., Kornfield, I., Krane, D., Mnookin, J. L., Rosenthal, R., Saks, M. J. \& Zabell, S. L. (2014). Regarding Champod, editorial: Research focused mainly on bias will paralyse forensic science. Science \& Justice. 54 (6), 508-511. https://doi.org/10.1016/j.scijus.2014.06.002

[47] Morgan, R. M. (2017b). Conceptualising forensic science and forensic reconstruction. Part II: The critical interaction between research, policy/law and practice. Science and Justice, 57(6), 460-467. https://doi.org/10.1016/j.scijus.2017.06.003

[48] Buckleton, J. S., Evett, I., \& Weir, B. (2014). Letter to editor in response to editorial by Risinger et al. Science \& Justice, p. 510. Elsevier.

https://doi.org/10.1016/j.scijus.2014.07.003

[49] Morgan, R. M. (2018c) Forensic science needs the 'hedgehog' and the 'fox'. Forensic Science International 292: e10-e12.

[50] Tangen, J. M., Thompson, M. B., \& McCarthy, D. J. (2011). Identifying fingerprint expertise. Psychological Science, 22, 995-997.

[51] Petraco, N. D., Shenkin, P., Speir, J., Diaczuk, P., Pizzola, P. A., Gambino, C., \& Petraco, N. (2012). Addressing the National Academy of Sciences' challenge: a method for statistical pattern comparison of striated tool marks. Journal of forensic sciences, 57(4), 900911.

[52] J. L. Mnookin, S. A. Cole, I. E. Dror, B. Fisher, M. M. Houck, K. Inman, D. H. Kaye, J. J. Koehler, G. Langenburg, D. M. Risenger, N. Rudin, J. Siegel, and D. A. Stoney, The need for a research culture in the forensic science. 58 UCLA Law Review 725 (2011) 725-779.

[53] Morgan, R. M., Cohen, J., McGookin, I., Murly-Gotto, J., O Connor, R., Muress, S., Freudiger-Bonzon, J. \& Bull, P. A. (2009). The relevance of the evolution of experimental studies for the interpretation and evaluation of some trace physical evidence. Science and Justice. 49, 277-285.

[54] Margot, P. (2011) Forensic science on trial - what is the law of the land? Australian Journal of Forensic Sciences. 43 (2-3) (2011) 89-103.

[55] Crispino, F., Ribaux, O., Houck, M., \& Margot, P. (2011). Forensic science - a true science? Australian. Journal of Forensic Sciences. 43 (2-3) 157-176.

[56] Ribaux, O., Bayon, A., Lock, E., Delemont, O., Roux, C., Zingg, C., \& Margot, P. (2010). Intelligence-led crime scene processing. Part II: Intelligence and crime scene examination. Forensic science international 199 (1-3) 63-71.

[57] The Forensic Science Regulator, Annual Report November 2016 - November 2017, (2018) available at:

https://assets.publishing.service.gov.uk/government/uploads/system/uploads/attachment data/file/674761/FSRAnnual Report 2017 v1 01.pdf [last accessed 30th July 2019] 
[58] Biedermann, A., Bozza, S., \& Taroni, F. (2016). The decisionalization of individualization. Forensic Science International, 266, 29-38.

[59] Biedermann, A., Bozza, S., Garbolino, P., \& Taroni, F. (2012). Decision-theoretic analysis of forensic sampling criteria using bayesian decision networks. Forensic Science International, 223(1-3), 217-27. https://doi.org/10.1016/j.forsciint.2012.09.003

[60] Gittelson, S., Bozza, S., Biedermann, A., \& Taroni, F. (2013). Decision-theoretic reflections on processing a fingermark. Forensic Science International, 226(1-3), e42-7. https://doi.org/10.1016/j.forsciint.2013.01.019

[61] Ask, K., \& Granhag, P. A. (2005). Motivational sources of confirmation bias in criminal investigations: the need for cognitive closure. Journal of Investigative Psychology and Offender Profiling, 2(1), 43-63. https://doi.org/10.1002/jip.19

[62] Englich, B., \& Musseweiler, T. (2001). Sentencing Under Uncertainty: Anchoring Effects in the Courtroom. Journal of Applied Social Psychology, 31(7), 1535-1551.

[63] Martire, K. A., Kemp, R. I., Watkins, I., Sayle, M. A., \& Newell, B. R. (2013). The expression and interpretation of uncertain forensic science evidence: Verbal equivalence, evidence strength, and the weak evidence effect. Law and Human Behavior, 37(3), 197-207.

[64] Musseweiler, T., \& Englich, B. (2005). Subliminal anchoring: Judgmental consequences and underlying mechanisms. Organizational Behavior and Human Decision Processes, 98, 133-143.

[65] van den Eeden, C. A. J., de Poot, C. J., \& van Koppen, P. J. (2016). Forensic expectations: Investigating a crime scene with prior information. Science and Justice, 56(6), 475-481. https://doi.org/10.1016/j.scijus.2016.08.003

[66] Dror, I. E., Morgan, R., Rando, C. \& Nakhaeizadeh, S. (2017). The bias snowball and the bias cascade effects: Two distinct biases that may impact forensic decision making. Journal of Forensic Sciences, 62 (3), 832-833.

[67] Earwaker, H., Morgan, R. M., Harris, A. J. L., \& Hall, L. J. (2015). Fingermark submission decision-making within a UK fingerprint laboratory: Do experts get the marks that they need? Science \& Justice, 55(4), 239-47. https://doi.org/10.1016/j.scijus.2015.01.007

[68] Morgan, R. M. (2018b). Forensic science: a conceptual overview of reconstruction, detection and disruption. In Wortley, R., Sidebottom, A. and Laycock, G. (Eds) Handbook of Crime Science. Abingdon, Routledge. pp190-203

[69] Annett, J., Duncan, K.D., Stammers, R.B. \& Gray, M.J. (1971). Task Analysis, London: HMSO. Training Information Paper No. 6

[70] Shepherd, A. (1985). Hierarchical Task Analysis and Training Decisions. PLET: Programmed Learning \& Educational Technology, 22(2), 162-176. https://doi.org/10.1080/1355800850220209

[71] Militello, L., \& Hutton, R. (1998). Applied cognitive task analysis (ACTA): a practitioner's toolkit for understanding cognitive task demands. Ergonomics. 41(11), 1618-1641.

[72] Smith, P. A., Baber, C., Hunter, J., \& Butler, M. (2008). Measuring team skills in crime scene investigation: Exploring ad hoc teams. Ergonomics, 51(10), 1463-1488. https://doi.org/10.1080/00140130802248076 
[73] Fraser, J., \& Williams, R. (2009). Handbook of forensic science. Willan Cullompton.

[74] Morgan, R., M., Nakhaeizadeh, S., Earwaker, H., Rando, C., Harris, A., J., L. \& Dror, I., E. (2018). Interpretation of evidence (cognitive decision making under uncertainty at every step of the forensic science process), in

R. Wortley, A. Sidebottom, G. Laycock, N. Tilley (Eds.), Handbook of Crime

Science, Routledge, Abingdon.

[75] Findley, K. A., \& Scott, M. S. (2006). The multiple dimensions of tunnel vision in criminal cases. Wisconsin Law Review, 2(2005), 292-397.

[76] Murrie, D. C., Boccaccini, M. T., Guarnera, L. A., \& Rufino, K. A. (2013). Are forensic experts biased by the side that retained them? Psychological Science, 24 (10), 1889-1897. https://doi.org/10.1177/095679761381812

[77] Findly, K. A. (2010). Tunnel vision conviction of the innocent: Lessons from psychological research, in B. Cutler, ed. Univ. of Wisconsin Legal Studies Research Paper, APA Press.

[78] Wallace, W. A. (2016). The Effect of Confirmation Bias in Criminal Investigative Decision Making. Doctoral thesis retrieved from:

https://scholarworks.waldenu.edu/cgi/viewcontent.cgi?referer=https://www.google.com/ \&httpsredir $=1 \&$ article $=1021 \&$ context $=$ hodgkinson

[79] O'Brien, B. (2009). Prime suspect: An examination of factors that aggravate and counteract confirmation bias in criminal investigations. Psychology, Public Policy, and Law, 15(4), 315-334.

[80] Risinger, D. M., Saks, M. J., Thompson, W. C., \& Rosenthal, R. (2002). The

Daubert/Kumho implications of observer effects in forensic science: Hidden problems of expectation and suggestion. California Law Review, 90 (1), 1-56. https://doi.org/10.2307/3481305

[81] Smith, L. L., \& Bull, R. (2013). Exploring the Disclosure of Forensic Evidence in Police Interviews with Suspects. Journal of Police and Criminal Psychology, 29 (2), 81-86. https://doi.org/10.1007/s11896-013-9131-0

[82] Richmond, K. (2018). Streamlined Forensic Reporting: "Swift and sure justice"? Journal of Criminal Law. 82 (2), 156-177. https://doi.org/10.1177/0022018318772701

[83] Forensic Science Regulator. (2016). Codes of Practice and Conduct for Forensic Science providers and practitioners in the Criminal Justice System.

[84] Cole, S. A. (2012). Forensic Science and Wrongful Convictions: From Exposer to Contributor to Corrector. New England Law Review, 46 (4).

[85] Dror, I., \& Langenburg, G. (2018). "Cannot Decide": The Fine Line Between Appropriate Inconclusive Determinations Versus Unjustifiably Deciding Not To Decide. Journal of Forensic Sciences. In press: 10.1111/1556-4029.13854.

[86] Howes, L. M. (2015). The communication of forensic science in the criminal justice system: A review of theory and proposed directions for research. Science \& Justice, 55 (2), 145-54. https://doi.org/10.1016/j.scijus.2014.11.002

[87] Smit, N. M., Lagnado, D. A., Morgan, R. M., \& Fenton, N. E. (2016). Using Bayesian 
networks to guide the assessment of new evidence in an appeal case. Crime Science, 5(1), 9. https://doi.org/10.1186/s40163-016-0057-6

[88] Taroni, F., Biedermann, A., \& Bozza, S. (2014). Bayesian networks for probabilistic inference and decision analysis in forensic science. Chichester: John Wiley \& Sons Ltd.

[89] Earwaker, H. (2017). An investigation of fingermark submission decision making. Doctoral Thesis. Retrieved from http://discovery.ucl.ac.uk/1542367/1/Earwaker\%2C H.

[90] Raymond, T. \& Julian, R. (2015). Forensic intelligence in policing: organisational and cultural change. Australian Journal of Forensic Sciences, 47 (4), 371-385.

[91] Doak, S. W. \& Assimakopoulos, D. (2010). Tacit knowledge: A needed addition to standard operating procedures. Science and Justice, 50 (1), 2.

[92] Morgan, R. M. \& Bull, P. A. (2007). The philosophy, nature and practice of forensic sediment analysis. Progress in Physical Geography, 31 (1), 43-58.

[93] Hall, L. J., \& Player, E. (2008). Will the introduction of an emotional context affect fingerprint analysis and decision-making? Forensic Science International, 181(1-3), 369. https://doi.org/10.1016/j.forsciint.2008.08.008

[94] Brauner, P. (2012). RE. "Subjectivity and bias in forensic DNA mixture interpretation" (Dror and Hapikian Volume 51 Issue 4). Science \& Justice, 52(2), 131. https://doi.org/10.1016/j.scijus.2012.04.001

[95] Cooper, G. S., \& Meterko, V. (2019). Cognitive bias research in forensic science: a systematic review. Forensic Science International. In press: https://doi.org/10.1016/J.FORSCIINT.2019.01.016

[96] Langenburg, G., Champod, C., \& Wertheim, P. (2009). Testing for potential contextual bias effects during the verification stage of the ACE-V methodology when conducting fingerprint comparisons. Journal of Forensic Sciences, 54 (3), 571-582. https://doi.org/10.1111/j.1556-4029.2009.01025.x

[97] Mattijssen, E. J. A. T., Kerkhoff, W., Berger, C. E. H., Dror, I. E., \& Stoel, R. D. (2016). Implementing context information management in forensic casework: Minimizing contextual bias in firearms examination. Science \& Justice, 56 (2), 113-122. https://doi.org/10.1016/j.scijus.2015.11.004

[98] Edmond, G., Tangen, J., M., Searston, R, A., \& Dror, I., E. (2015); Contextual bias and cross-contamination in the forensic sciences: the corrosive implications for investigations, plea bargains, trials and appeals. Law, Probability and Risk, 14 (1), 1-25.

[99] Santoro, V., Lubelli, S., De Donno, A., Inchingolo, A., Lavecchia, F., \& Introna, F. (2017). Photogrammetric 3D skull/photo superimposition: A pilot study. Forensic Science International, 273, 168-174. https://doi.org/10.1016/J.FORSCIINT.2017.02.006

[100] Ma, M., Zheng, H., \& Lallie, H. (2010). Virtual Reality and 3D Animation in Forensic Visualization. Journal of Forensic Sciences, 55 (5), 1227-1231. https://doi.org/10.1111/j.1556-4029.2010.01453.x

[101] Koller, S., Ebert, L. C., Martinez, R. M., \& Sieberth, T. (2019). Using virtual reality for forensic examinations of injuries. Forensic Science International, 295, 30-35. https://doi.org/10.1016/J.FORSCIINT.2018.11.006

[102] Williams, A., Rogers, C. J., \& Cassella, J. P. (2019). Does the UK need a Human 
Taphonomy Facility? Forensic Science International.

https://doi.org/10.1016/J.FORSCIINT.2019.01.010

[103] Shackleton, D., Gray, N., Ives, L., Malsom, S., \& Vanhinsbergh, D. (2019).

Development of RapidHIT® ID using NGMSElectTM Express chemistry for the processing of reference samples within the UK criminal justice system. Forensic Science International, 295, 179-188. https://doi.org/10.1016/J.FORSCIINT.2018.12.015

[104] de Ronde, A., van Aken, M., de Puit, M., \& de Poot, C. (2019). A study into fingermarks at activity level on pillowcases. Forensic Science International, 295, 113120. https://doi.org/10.1016/J.FORSCIINT.2018.11.027

[105] Francese, S., Bradshaw, R., \& Denison, N. (2017). An update on MALDI mass spectrometry based technology for the analysis of fingermarks - stepping into operational deployment. The Analyst. 142. 10.1039/C7AN00569E.

[106] Devine, D. J., Clayton, L. D., Dunford, B. B., Seying, R., \& Pryce, J. (2001). Jury Decision Making; 45 Years of Empirical Research on Deliberating Groups, Psychology Public Policy, and Law 7 (3), 622-727. https://doi.org/10.1037/1076-8971.7.3.622

[107] Bright, D. A., \& Goodman-Delahunty, J. (2006). Gruesome Evidence and Emotion: Anger, Blame, and Jury Decision-Making. Law and Human Behavior, 30(2), 183-202. https://doi.org/10.1007/s10979-006-9027-y

[108] Thomas, C. (2008) Exposing the myths of jury service. Criminal Law Review, 6, 415.

[109] Thomas, C. (2010) Are juries fair? Ministry of Justice Research Series 1/10, London: Ministry of Justice.

[110] Brennan, P. A., Konieczny, K., Groves, J., Parker, M., Sherman, K. P., Foulkes, J., Hills, S., \& Featherstone, C. (2015). Development, validation and initial outcomes of a questionnaire to examine human factors in postgraduate surgical objective structured clinical examinations. British Journal of Surgery, 102(4), 423-430.

https://doi.org/10.1002/bjs.9721

[111] Dror, I. E., Kosslyn, S. M., \& Waag, W. L. (1993). Visual-spatial abilities of pilots. Journal of Applied Psychology. 78 (5), 763.

[112] Edmond, G., Towler, A., Growns, B., Ribeiro, G., Found, B., White, D., Ballantyne, K., Searston, R., Thompson, M., B., Tangen, J. M., Kemp, R. I., \& Martire, K. (2017). Thinking forensics: Cognitive science for forensic practitioners. Science and Justice, 57, 144-154. https://doi.org/10.1016/j.scijus.2016.11.005

[113] Stewart, N., Chater, N. \& Brown, G. D. A., (2006). Decision by sampling. Cognitive Psychology. 53 (1), 1-26

[114] Parducci, A. (1965). Category judgment: A range frequency model. Psycho- logical Review, 72, 407-418.

[115] Parducci, A. (1995). Happiness, pleasure, and judgment: The contextual theory and its applications. Mahwah, NJ: Erlbaum.

[116] Helson, H. (1947). Adaptation-level as frame of reference for prediction of psychophysical data. The American Journal of Psychology, 60,1-29.

[117] Chesters, M. S. (1992). Human visual perception and ROC methodology in medical imaging. Physics in Medicine and Biology, 37, 1433-1476. 
https://doi.org/10.1088/0031-9155/37/7/001

[118] Phillips, V. L., Saks, M. J. \& Peterson, J. L. (2001). The application of signal detection theory to decision making in forensic science. Journal of Forensic Sciences. 46 (2), 294 308.

[119] Kahneman, D., Slovic, P. \& Tversky, A. (Eds). (1982). Judgement under uncertainty: Heuristics and Biases. Cambridge: Cambridge University Press.

[120] Prescott, K., Milne, B. \& Clarke, J., (2011). How effective is the enhanced cognitive interview when aiding recall retrieval of older adults specifically with regards to conversation, In: Journal of Investigative Psychology and Offender Profiling 8, (3), 257270.

[121] Earwaker, H., Charlton, D., \& Bleay, S. (2015). Fingerprinting - the UK landscape: processes, stakeholders and interactions. Forensic Science Knowledge Transfer Network.

[122] Forensic Science Regulator. (2015). Cognitive bias effects relevant to forensic science examinations.

[123] Daubert v. Merrell Dow Pharmaceuticals, Inc. 509, US, 579 (1993).

[124] Christensen, A. M., Crowder, C. M., Ousley, S. D. \& Houck, M. M. (2014). Error and its meaning in forensic science. Journal of Forensic Sciences. 59 (1), 123-6.

[125] Frese, M. \& Keith, N. (2015). Action errors, error management, and learning in organizations. Annual Review of Psychology. 66 (1), 661-687.

[126] Cole, S. A. (2005). More than zero: accounting for error in latent fingerprint identification. The Journal of Criminal Law and Criminology. 95 (3), 985-1078.

[127] Frese, M., Brodbeck, F., Heinbokel, T., Mooser, C., Schleiffenbaum, E. \& Thiemann, P. (1991). Errors in training computer skills: on the positive function of errors. Human Computer Interaction. 6, 77-93.

[128] Reason, J. (1990). Human Error. Cambridge University Press, New York

[129] Mangels, J, A., Butterfield, B., Lamb, L., Good, C. \& Dweck, C. S. (2006). Why do beliefs about intelligence influence learning success? A social cognitive model. Social, Cognitive and Affective Neuroscience. 1, 75-86.

[130] Zakay, D., Ellis, S. \& Shevalsky, M. (2004). Outcome value and early warning indicators as determinations of willingness to learn from experience. Experimental Psychology. 51, 150-157.

[131] Wiegmann, D. A., \& Shappell, S. A. (2000). Human Error Perspectives in Aviation. The International Journal of Aviation Psychology. 11(4), 341-357.

[132]_Leitch, M. (2010), ISO 31000:2009-The New International Standard on Risk Management. Risk Analysis, 30, 887-892. doi:10.1111/j.1539-6924.2010.01397.x

[133] Roux, C., Crispino, F. \& Ribaux, O. (2012). From forensics to forensic science. Current Issues in Criminal Justice. 24 (1), 7-24.

[134] Morgan, R. M., Flynn, J., Sena, V. \& Bull. P. A. (2014). Experimental forensic studies of the preservation of pollen in vehicle fires Science and Justice 54(2):141-145. 
[135] Bowman, V. (Ed). (1998 (revised 2002, 2004, 2009, 2014)) Manual of fingerprint development techniques, 2nd edition. ISBN 185893 9720. London: Home Office

[136] Sears, V. G., Bleay, S. M., Bandey, H. L. \& Bowman, V. J. (2012). A methodology for fingermark research. Science and Justice. 52, 145-160.

[137] Stoel, R. D., Berger, C., Kerkhoff,,W., Mattijssen, E. \& Dror, I. (2014). Minimizing Contextual Bias in Forensic Casework, in: Eds. Hickman, M., and Strom, K., Forensic Science and the Administration of Justice: Critical Issues and Directions, SAGE Publishing, pp.67-86.. 